\title{
Infrared induced conformational change in the two strong hydrogen bonded complexes 2-1 between dimethyl ether and hydrogen iodide in nitrogen matrix
}

\author{
A. Schriver, S. Racine, ${ }^{*}$ O. Schrems $\dagger$ and L. Schriver-Mazzuoli \\ Laboratoire de Physique Moléculaire et Applications, CNRS UPR 136, Université P. et M. Curie, Boite 76, \\ 4 Place Jussieu, 75252 Paris Cedex 05, France
}

(Received 26 January 1993; in final form 1 April 1993; accepted 4 April 1993)

\begin{abstract}
The IR spectra of the complexes between dimethylether (DME) and hydrogen iodide in nitrogen matrices were reinvestigated with careful attention to the temperature and IR radiation effects upon the higher aggregates. Irradiation using a broad band IR source was found weakly active leading to a nearly stationary population of the two (DME) ${ }_{2} \mathrm{H}^{+} \mathrm{I}^{-}$species. Irradiation with $\mathrm{CO}_{2}$ laser lines induced a conformational interconversion of both aggregates to non-hydrogen-bonded forms. The breaking of the strong hydrogen bond was principally governed by irradiation in the range $2600-1500 \mathrm{~cm}^{-1}$ corresponding to the $\delta \mathrm{CH}_{3}$ region whereas the reverse process was observed by increasing temperature above $27 \mathrm{~K}$ under the annealing limit or irradiation below $1100 \mathrm{~cm}^{-1}$. No accurate evidence was found for the occurrence of photochemical proton transfer between the centrosymmetrical and asymmetrical cations characterizing the two investigated complexes.
\end{abstract}

\section{INTRODUCTION}

THE PROTON transfer process between two interacting molecules is one of the most interesting problems in the hydrogen bonding phenomenon. It is governed both by the proton affinities of the opposing groups (Ref. [1] and others cited therein) and by environmental effects [2]. Recently it has been shown that the reaction proton transfer takes place in the electronically excited state of the neutral clusters formed in free jetcooled supersonic expansion [3] or isolated in low temperature rare gas matrices [4]. Besides, recent studies in matrices showed that a large class of hydrogen bonded systems involving $\mathrm{HI}$ as proton donor were IR photosensitive (Refs $[5,6]$ and others cited therein). In this view, it could be expected that a single quantum of excitation of a $(B)_{n}(\mathrm{HI})_{m}$ cluster vibrational mode could induce proton motion by a structural change in a part of the cluster as was recognized by the end of the 1970 s $[7,8]$. In this paper, we explore this idea showing the effects of monochromatic $\mathrm{CO}_{2}$ laser or broad band (globar) irradiation on the two strong hydrogen bonded 2-1 complexes involving dimethylether (DME) and hydrogen iodide, previously identified in nitrogen matrices as ion pairs $(D M E)_{2} \mathrm{H}^{+} \mathrm{I}^{-}$[9]. The first one, IR photosensitive, was characterized by a centrosymmetrical potential function for the proton, whereas the second one showed a proton potential function probably of the symmetrical double minimum type. The one-to-one complex was not accurately identified but it was not surprising as since that time it has been observed that complexes of $\mathrm{HI}$ with weak to medium strength bases quickly dissociate in the beam of the spectrometer at low temperature [6]. Also we briefiy reinvestigated the DME-HI system trapped in nitrogen, and then we give results on the irradiation of the two cations $(\mathrm{DME})_{2} \mathrm{H}^{+} \mathrm{I}^{-}$.

\section{EXPERIMENTAL}

Most of the experiments were performed in Paris with some complementary ones done in Siegen. Thus two cryostats have been used in this work: a conventional liquid helium cryostat

\footnotetext{
* Present address: Laboratoire de Spectrochimie Moléculaire CNRS URA 508, Université P. et M. Curie, 4 Place Jussieu, 75252 Paris Cedex 05, France.

† Present address: A.W.I. Columbus Strasse, Bremerhaven.

¥ Author to whom correspondence should be addressed.
} 
capable of maintaining constant temperatures between 10 and $50 \mathrm{~K}$ for 6 to $8 \mathrm{~h}$ and a closed cycle Air Product displex refrigerator, model 202A. The gas mixtures were prepared by standard manometric techniques and sprayed through a dual jet system onto the cold window (ICs or gold copper mirror) maintained at $17 \mathrm{~K}$, at $5 \mathrm{mmol} / \mathrm{h}$. Dimethyl ether (purchased from Fluka) was dried over sodium then quickly distilled and outgassed by condensation and thawing cycles under vacuum. Nitrogen for the matrices (Air Liquide N50) was used without further purification. Infrared spectra were recorded either with a Perkin-Elmer model 580 spectrometer at $0.9 \mathrm{~cm}^{-1}$ resolution with a frequency accuracy of $0.4 \mathrm{~cm}^{-1}$ or in some cases with a Bruker 113V FTIR spectrophotometer at $0.5 \mathrm{~cm}^{-1}$ resolution. Infrared irradiations of the sample were carried out with the $1500 \mathrm{~K}$ globar source of the spectrometers using broad band filters listed in Table 3 and with $\mathrm{CW} \mathrm{CO}_{2}$ lasers. The first one (Paris), home built $(6 \mathrm{~mm}$ diameter), was used at a laser power of about $300 \mathrm{~mW} \mathrm{~cm}^{-2}$ while the second one (Siegen), an Apollo Lasers Model $570 \mathrm{CO}_{2}$ laser, was used at $1.5 \mathrm{~W}$ with a Si plate.

\section{REsults AND Discussion}

\section{Identification of $(\mathrm{DME})_{\mathrm{m}}(\mathrm{HI})_{\mathrm{n}}$ species}

One-to-one complex. At high dilution in HI and DME-H6 (typically HI/DME/Ar $1 / 1 / 1500$ ), the spectrum recorded at $11 \mathrm{~K}$ after deposition at $20 \mathrm{~K}$ did not show the characteristic band of a hydrogen-bonded HI molecule $\left(v_{\mathrm{s}}\right)$. Only new weak doublets at $1094.5-1093.0 \mathrm{~cm}^{-1}$ and at $919.4-917.2 \mathrm{~cm}^{-1}$ appeared, respectively, in the $v_{\mathrm{as}}$ COC and $v_{\mathrm{s}}$ COC mode regions of the DME-H6 molecule. Significant changes occurred when the previous sample was recorded at $29 \mathrm{~K}$. A new weak broad absorption was observed at $1950 \mathrm{~cm}^{-1}$. In addition, in the $v_{\text {as }}$ and $\nu_{\mathrm{s}}$ COC region, features as previously reported decreased with appearance of new bands respectively at $1087-1084 \mathrm{~cm}^{-1}$ and $906 \mathrm{~cm}^{-1}$. All these new bands vanished when the sample was again cooled to $11 \mathrm{~K}$ and exposed to the light of the spectrophotometer for $2 \mathrm{~h}$. Figure 1 summarizes the observed typical effects which were completely reversible. Substitution of HI by DI showed a different trend. After deposition and recording at low temperature a broad band centred at about $1380 \mathrm{~cm}^{-1}\left(v_{\mathrm{s}}\right)$ was observed and appeared insensitive to IR irradiation. These overall
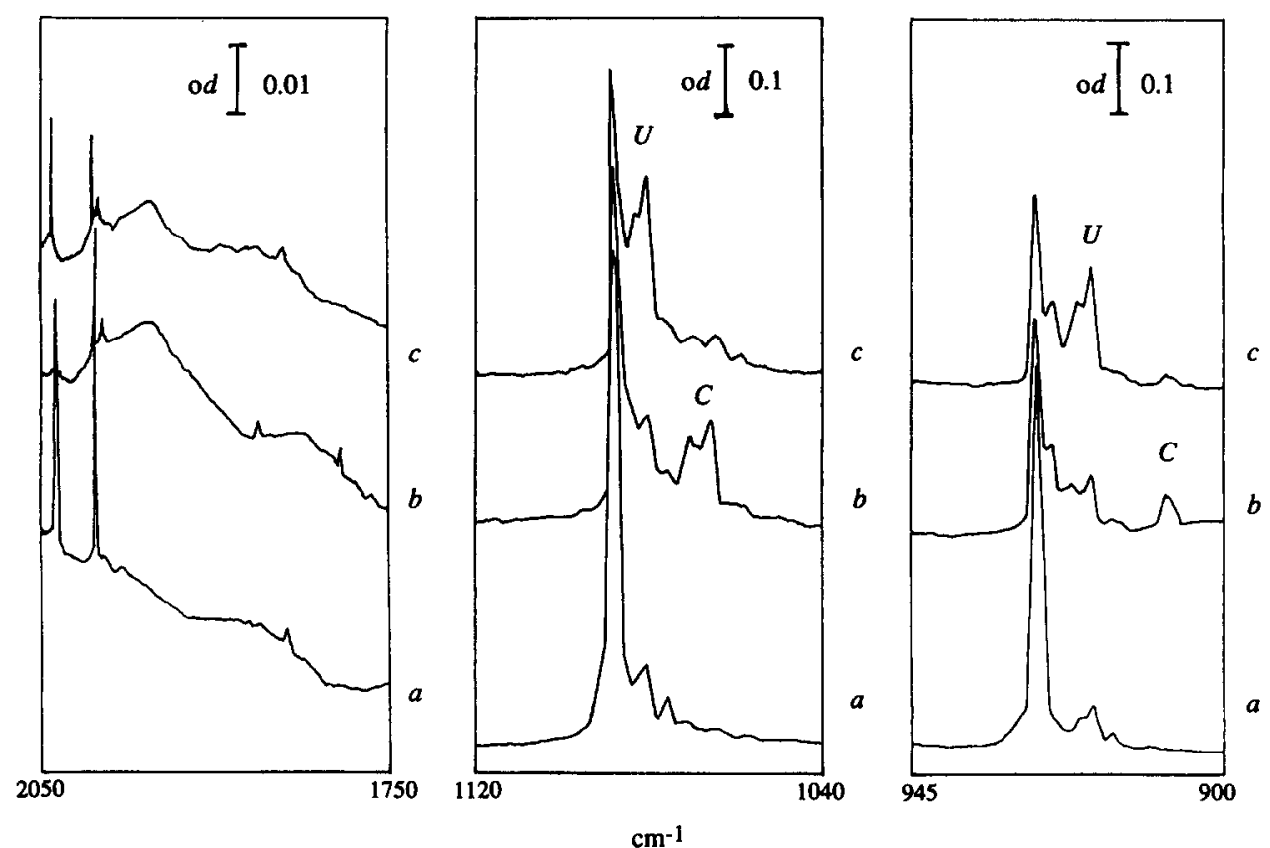

Fig. 1. Spectral changes for a $D M E / H I / N_{2}=1 / 1 / 1500$ mixture in the $2100-1800 \mathrm{~cm}^{-1}$ and $1200-900 \mathrm{~cm}^{-1}$ domains. (a) after deposition at $20 \mathrm{~K}$ in the dark, recording temperature $T_{\mathrm{s}}=11 \mathrm{~K}$; (b) after $5 \mathrm{~min}$ warming at $29 \mathrm{~K}$ in the dark, recording temperature $T_{3}=29 \mathrm{~K}$; (c) as for (b), followed by $2 \mathrm{~h}$ irradiation in the beam of the 580 Perkin-Elmer spectrometer at $T_{\mathrm{s}}=11 \mathrm{~K}$. 
Table 1. Characteristic vibration frequencies $\left(\mathrm{cm}^{-1}\right)$ of the one-to-one complex DME:HI in nitrogen matrix

\begin{tabular}{llcl}
\hline & & \multicolumn{2}{c}{ DME:HI complex } \\
Mode & DME monomer & U form & C form \\
\hline$v_{\mathrm{s}}$ COC & $925.0^{*}$ & $919.4-917.2$ & 906 \\
$\nu_{\mathrm{s}}$ COC & $1096.8 \dagger$ & $1094.5-1093$ & $1087-1084$ \\
$v_{\mathrm{s}}$ HI & - & $2237 \ddagger$ & 1950 \\
\hline
\end{tabular}

* Weak satellites at 928,920 and $915 \mathrm{~cm}^{-1}$. + Weak satellites at 1098 and $1089.2 \mathrm{~cm}^{-1}$. $\ddagger$ Close to HI monomer band.

observations are similar to those described for the other 1-1 hydrogen bonded complexes trapped in inert matrices with $\mathrm{HI}$ as proton donor. The band at $1950 \mathrm{~cm}^{-1}$ is the HI stretching mode $\left(v_{s}\right)$ of the hydrogen bonded complex (C) which photodissociates through a new orientation of $\mathrm{HI}[10]$ in a non-hydrogen-bonded pair $\mathrm{U}$ characterized by a $\mathrm{HI}$ frequency close to that of free HI and some weak shifted bands of complexed DME. Experimental results are collected in Table 1. Some irradiation experiments carried out with filters led to the conclusion that, as observed for HI-acetone [11] and the HI-ethylene oxide [12] systems, the $\mathrm{C} \rightarrow \mathrm{U}$ barrier height is greater than $1400 \mathrm{~cm}^{-1}$, the vibrational excitation efficiency being the $v_{\mathrm{HI}}$ mode. Due to the barrier height, photodissociation of the isotopic (DME) - . DI doesn't occur. The reversible $U \rightarrow C$ conversion observed by the thermal process at $30 \mathrm{~K}$ would imply a barrier height of about $3 \mathrm{~kJ} / \mathrm{mol}$ as previously reported.

Higher aggregates. After progressive increasing of the temperature above $27 \mathrm{~K}$ for samples relatively diluted in both dopants (typically $\mathrm{HI} / \mathrm{DME} / \mathrm{N}_{2} 1 / 2 / 1000$ ) new bands appeared in the spectra. Careful comparison of the different spectra as displayed for examples in Fig. 2 allowed us to distinguish four distinct new species (referred to hereafter as $\left.\mathbf{A g}_{1}, \mathbf{A g}_{2}, \mathbf{A g}_{3}, \mathbf{A g}_{4}\right)$ mainly characterized by absorption groups which appeared at about: (i) $660,1200 \mathrm{~cm}^{-1}$; (ii) $1015,830 \mathrm{~cm}^{-1}$ (iii) $830,1300,1800 \mathrm{~cm}^{-1}$; and

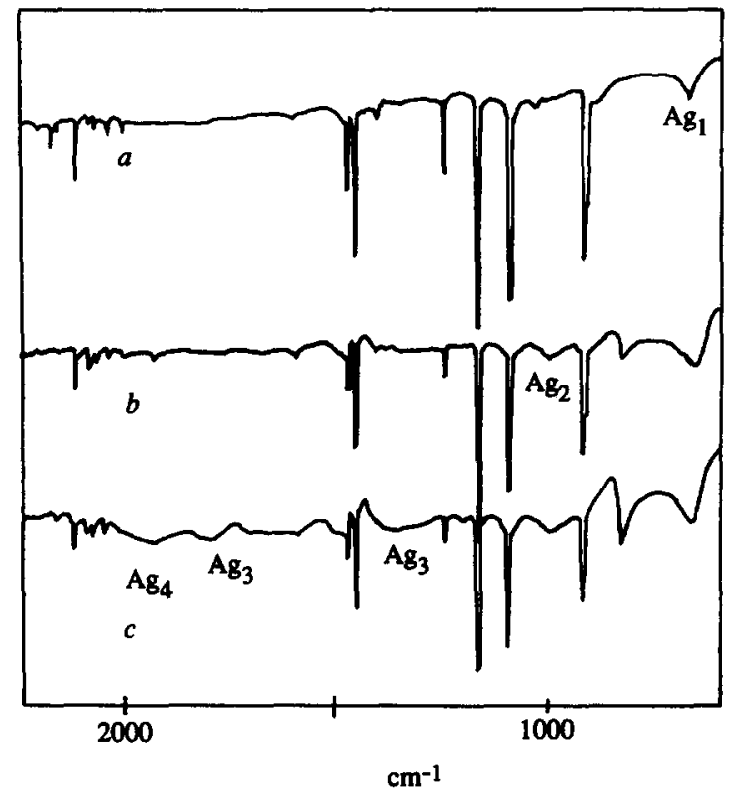

Fig. 2. Typical spectra for $\mathrm{DME} / \mathrm{HI} / \mathrm{N}_{2}$ samples $1 / 2 / 1000$ recorded at $11 \mathrm{~K}$ either after deposition or various warming up temperatures showing the appearance of different aggregates. (a) After deposition; (b) after warming at $27 \mathrm{~K}$ and recooling at $11 \mathrm{~K}$; (c) after warming at $30 \mathrm{~K}$ and recooling at $11 \mathrm{~K}$. 
Table 2. Frequencies $\left(\mathrm{cm}^{-1}\right)$ and tentative assignment of the characteristic absorptions of the different $(\mathrm{DME})_{m}(\mathrm{HI})_{n}$ aggregates in nitrogen matrix

\begin{tabular}{|c|c|c|c|c|}
\hline $\mathrm{Ag}_{1}{ }^{*}$ & $\mathrm{Ag}_{2} \dagger$ & $\mathrm{Ag}_{3} \ddagger$ & $\mathrm{Ag}_{4} \S$ & Assignment \\
\hline $\begin{array}{l}1456.9 \\
1208.0 \\
1165.0 \\
1092.5 \\
919.7-917.2 \\
\\
690-660\end{array}$ & $\begin{array}{r}833 \\
1000\end{array}$ & $\begin{array}{c}980 \\
833-817 \\
1300\end{array}$ & 1900 & $\begin{array}{l}v(\mathrm{IH})_{2} \cdots \mathrm{O} \\
v(\mathrm{HI})_{n} \cdots \cdot \mathrm{I}^{-} \\
\delta\left(\mathrm{CH}_{3}\right) \\
\delta(\mathrm{OHO})(?) \\
v_{\mathrm{as}} \mathrm{COC}+\mathrm{r} / /\left(\mathrm{CH}_{3}\right)+\mathrm{r} \perp\left(\mathrm{CH}_{3}\right) \\
v_{\mathrm{as}} \mathrm{COC} \\
v_{\mathrm{s}} \mathrm{COC} \\
v\left(\mathrm{O} \cdots \mathrm{H}^{\prime} \cdots\right)^{+} \\
v(\mathrm{OHO})^{+}\end{array}$ \\
\hline
\end{tabular}

* $\mathrm{Ag}_{1}$ : symmetrical (DME) $\mathrm{H}^{+} \mathrm{I}^{-}$cation.

$+\mathrm{Ag}_{2}$ : asymmetrical (DME) ${ }_{2} \mathrm{H}^{+} \mathrm{I}^{-}$cation.

$\ddagger \mathrm{Ag}_{3}$ : asymmetrical (DME) ${ }_{2} \mathrm{H}^{+} \mathrm{I}^{-}(\mathrm{HI})_{n}$ cation.

$\S \mathrm{Ag}_{4}$ : (DME) $)_{2} \mathrm{HI}$ complex.

(iv) $1900 \mathrm{~cm}^{-1}$ with different relative intensity according to the annealing process. These observations bring new insight upon those previously described in the first paper [9] where strong annealings were made upon more concentrated samples. Thus new assignment of obtained spectra is tentatively proposed.

As previously reported, the $660 \mathrm{~cm}^{-1}$ absorption is the antisymmetric hydrogen stretch of the symmetrical $\mathrm{O} \cdots \mathrm{H}^{+} \cdots \mathrm{O}$ cation $\left(\mathrm{Ag}_{1}\right)$ characterizing a nearly perfect proton sharing between the two oxygen atoms. This band $\left(\mathrm{FWHH}=60 \mathrm{~cm}^{-1}\right)$, recorded in the absence of $\mathrm{CO}_{2}$ impurity in our sample, is composed of two unresolved components about 660 and $690 \mathrm{~cm}^{-1}$. The higher frequency component was not observed when $\mathrm{CD}_{3} \mathrm{OCD}_{3}$ was used in place of $\mathrm{CH}_{3} \mathrm{OCH}_{3}$ denoting that the band broadening can be due to a combination involving complexed low $\mathrm{CH}_{3}$ modes enhanced by Fermi resonance. The DME submolecule in the cation appeared very weakly perturbed. Only features at $917.2 \mathrm{~cm}^{-1}$ and at about $1500 \mathrm{~cm}^{-1}$ appeared as shoulders of respectively $v_{\mathrm{s}} \mathrm{COC}$ stretching and methyl bending of the isolated DME molecule.

Weak broad absorption centred at $1000 \mathrm{~cm}^{-1}$ showed a complex structure with two shoulders at 990 and $1010 \mathrm{~cm}^{-1}$. It grew in concert with the $830 \mathrm{~cm}^{-1}$ feature so much that annealings were weak without appearance of $\mathrm{HI}$ dimers increasing. With strong annealing or more concentrated samples as in Ref. [9] (DME/HI/N $\left.\mathrm{N}_{2} 1 / 1 / 200\right)$, the $830 \mathrm{~cm}^{-1}$ band grew stronger with the appearance of new bands at 1300 and $1800 \mathrm{~cm}^{-1}$, whereas the $990 \mathrm{~cm}^{-1}$ shoulder of the $1000 \mathrm{~cm}^{-1}$ band became prominent. These results suggest formation of an asymmetrical cation $(\mathrm{DME})_{2} \mathrm{H}^{+}$with two different anions: $\mathrm{I}^{-}\left(\mathrm{Ag}_{2}\right)$ and $\mathrm{I}^{-}(\mathrm{IH})_{n}\left(\mathrm{Ag}_{3}\right)$, the last one generated by strong annealing or more concentrated samples. In regard to the symmetrical cation $\left(\mathrm{Ag}_{1}\right)$, the asymmetrical cations have a hydrogen atom tipped towards one of the two oxygen atoms, the proton transfer being more important in the case of the higher aggregate $\mathrm{Ag}_{3}$. Thus the two strongest broad bands about 1000 and $1300 \mathrm{~cm}^{-1}$ could be assigned to the proton motion in $\mathrm{Ag}_{2}$ and $\mathrm{Ag}_{3}$, whereas the $1800 \mathrm{~cm}^{-1}$ band could be responsible for the $(\mathrm{HI})_{n}$ absorption. In these cations, the COC stretching modes are expected to be strongly shifted. Consequently the $v_{\mathrm{s}} \mathrm{COC}$ band is located at $830 \mathrm{~cm}^{-1}$ while the weaker $v_{\mathrm{a}} \mathrm{COC}$ feature probably falls in coincidence with the $v_{\mathrm{s}}$ absorption of $\mathrm{Ag}_{2}$. At higher dilution, the centrosymmetric cation $\left(\mathrm{Ag}_{1}\right)$ is favoured relative to the asymmetrical cation $\left(\mathrm{Ag}_{2}\right)$, whereas at high concentration, the asymmetrical $\left(\mathrm{Ag}_{3}\right)$ cation becomes the major species, the nonequivalent position of $\mathrm{I}^{-}$being stabilized by aggregation with $\mathrm{HI}$.

At last, the broad band at $1900 \mathrm{~cm}^{-1}$ in the $\mathrm{HI}$ region and the weak feature at $886 \mathrm{~cm}^{-1}$ in the $\nu_{\mathrm{s}} \mathrm{COC}$ stretching region were identified as the $1: 2 \mathrm{DME} \cdots(\mathrm{HI})_{2}$ species $\left(\mathrm{Ag}_{4}\right)$ by comparison with the HI-acetone system [11]. As for the 1:1 complex this species disappeared in the beam of the spectrophotometer and after long deposition at $20 \mathrm{~K}$ in the dark, it was not always observed.

All band positions are listed Table 2 . 


\section{Irradiation effects upon the two (DME) ${ }_{2} \mathrm{H}^{+} \mathrm{I}^{-}$cations $A g_{1}$ and $A g_{2}$}

The experiments to be discussed were performed at $11 \mathrm{~K}$ either after deposition or after sample warming between $27-29 \mathrm{~K}$ then recooling at $11 \mathrm{~K}$. Two kinds of irradiation experiments were carried out: polychromatic irradiation with the full light of the spectrometer source using also several broad band pass filters and monochromatic irradiation in the $10 \mu \mathrm{m}$ region of the $\mathrm{CO}_{2}$ lasers.

Polychromatic irradiation. Figure 3 shows the difference spectrum after irradiation for $12 \mathrm{~h}$ in the beam of the spectrophotometer (Bruker) of a HI/DME/ $\mathrm{N}_{2} 1 / 1 / 500$ sample previously annealed at $27 \mathrm{~K}$ and recooled at $11 \mathrm{~K}$. All the aggregate bands were sensitive to the irradiation and decreased in intensity with correlated intensity increase of DME complexed bands at $922.8,1095.9$ and $1167.1 \mathrm{~cm}^{-1}$. However the observed effects were very weak and after irradiation, a nearly similar stationary population for the two cations was observed. Other experiments were performed using several filters to study the influence of different spectral regions on the photoprocess. Results are summarized in Table 3. Again no noticeable changes were observed and thus did not allow direct kinetic studies. From the observations in Table 3, several remarks can be made: (i) except for the irradiation with filter 1 , the two cations showed the same behaviour; (ii) exposition to the range $2600-1500 \mathrm{~cm}^{-1}$ led to the loss of $\mathrm{Ag}_{1}$ and $\mathrm{Ag}_{2}$, whatever growth of the two species occured after irradiation below $2000 \mathrm{~cm}^{-1}$; (iii) the observed effect seemed to depend on the matrix history; thus irradiation with filter 4 gave observations in variance: decreasing in intensity of the overall bands when the irradiation was performed just after deposition or increasing the intensity of the same bands when the irradiation was performed after irradiation with filter 2 .

Monochromatic irradiation. Samples were irradiated using the possible coincidence between the absorption band frequencies of aggregates with the same $\mathrm{CO}_{2}$ laser lines emission of the $00^{\circ} 1-\left(10^{\circ} 0,02^{\circ} 0\right)$ transitions such as: R34 $\left(1086.9 \mathrm{~cm}^{-1}\right), \quad R 22$ $\left(1079.8 \mathrm{~cm}^{-1}\right), \quad R 46 \quad\left(990.6 \mathrm{~cm}^{-1}\right), \quad$ R50 $\quad\left(992.5 \mathrm{~cm}^{-1}\right), \quad R 38 \quad\left(986.5 \mathrm{~cm}^{-1}\right), \quad$ R34 $\left(984.3 \mathrm{~cm}^{-1}\right)$, R28 $\left(980.9 \mathrm{~cm}^{-1}\right), \mathrm{R} 6\left(966.2 \mathrm{~cm}^{-1}\right)$ and P8 $\left(955 \mathrm{~cm}^{-1}\right)$.

Significant successful irradiations were registered only with R22, R46, R50, R38 and $\mathrm{R} 34 \mathrm{CO}_{2}$ emission lines.

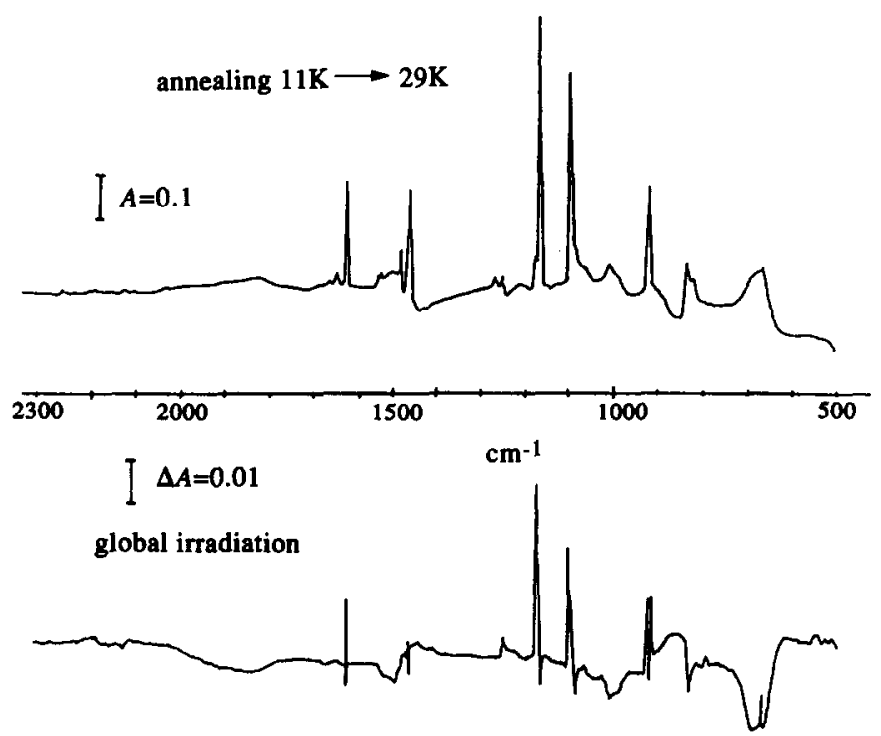

Fig. 3. Infrared spectra of a $\mathrm{DME} / \mathrm{HI} / \mathrm{N}_{2}=1 / 1 / 500$ sample. Upper trace: spectrum recorded at $11 \mathrm{~K}$ after annealing to $29 \mathrm{~K}$ for $10 \mathrm{~min}$. Lower trace: difference spectrum after-before global irradiation for $18 \mathrm{~h}$ (both spectra recorded at $11 \mathrm{~K}$ ). 
Table 3. Characteristics of the filters used in irradiation experiments with the spectrometer beam (PerkinElmer) and main observations in the $1100-600 \mathrm{~cm}^{-1}$ region after irradiation; $+:$ small cation population increase; - : small cation population decrease

\begin{tabular}{lccccc}
\hline & \multicolumn{2}{c}{ Characteristics } \\
Filters & $\begin{array}{c}\text { Transmission range } \\
\left(\mathrm{cm}^{-1}\right)\end{array}$ & $\begin{array}{c}\text { Transmission } \\
\text { percentage }\end{array}$ & $1000 \mathrm{~cm}^{-1}$ band & $830 \mathrm{~cm}^{-1}$ band & $690-660 \mathrm{~cm}^{-1}$ band \\
\hline 1 & $>2000$ & $62 \%$ & + & + & - \\
2 & $2600-1500$ & $70 \%$ & - & - & - \\
3 & $<2000$ & $60 \%$ & + & + & + \\
4 & $1200-400$ & $58 \%$ & - & - & $-\dagger$ \\
\hline
\end{tabular}

* Effect observed after irradiation with filter 2.

$\dagger$ Effect observed after deposition.

A sequence of photolysis with filter 2 and R46 is illustrated (Fig. 4) in the $1050-550 \mathrm{~cm}^{-1}$ spectral region. In the initial spectrum no sensitivity to the beam irradiation with filter 2 is shown in Fig. 4a. Photolysis at $990.6 \mathrm{~cm}^{-1}$ gave the spectrum in Fig. 4c. Characteristic bands of $\mathrm{Ag}_{1}$ and $\mathrm{Ag}_{2}$ aggregates strongly increased. In the higher frequency spectral region, the $1800 \mathrm{~cm}^{-1}$ absorption of $\mathrm{Ag}_{3}$ species also appeared. Furthermore the $\mathrm{HI}$ monomer absorption at $2237 \mathrm{~cm}^{-1}$ decreased in intensity without change in the dimer $(\mathrm{HI})_{2}$ absorptions. Subsequent photolysis of the sample in the beam of the spectrophotometer with filter 2 resulted in the spectrum Fig. 4d, nearly identical to that in Fig. 4a. Observed effects, also obtained with the R50, R38 and $\mathrm{R} 34 \mathrm{CO}_{2}$ lines, were not due to a temperature effect: the laser heating was less than $1 \mathrm{~K}$ and a similar trend arose at lower laser power by introducing two silicon filters which reduce the intensity. Similar experiments with previous $\mathrm{CO}_{2}$ lines were also carried out by inserting the filter 4 which allows only observation of the $1100-600 \mathrm{~cm}^{-1}$ region, between the $\mathrm{CO}_{2}$ source and the sample. In this case, the $906 \mathrm{~cm}^{-1}$ feature associated to the hydrogenbonded $\mathrm{C}$ form of the one-to-one DME-HI complex was observed. After irradiation, it showed no significant change in intensity leading to the conclusion that the observed photoprocess did not proceed through the one-to-one (C) DME-HI complex. The

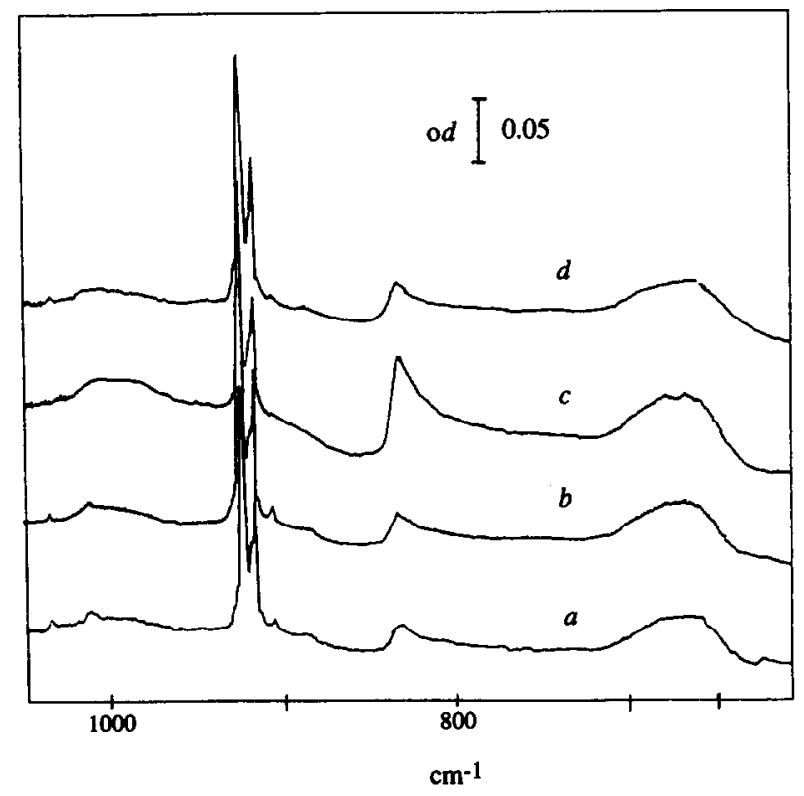

Fig. 4. Spectral changes for a $\mathrm{DME} / \mathrm{HI} / \mathrm{N}_{2} 1 / 2 / 1000$ mixture in the $1950-650 \mathrm{~cm}^{-1}$ domain. (a) After deposition at $20 \mathrm{~K}$ in the dark, recording temperature $T_{s}=11 \mathrm{~K}$; (b) after 30 min irradiation in the beam of the spectrophotometer with filter $2 ;$ (c) as for (b) followed by irradiation with $\mathrm{CO}_{2}$ laser line at $990.6 \mathrm{~cm}^{-1}$; (d) as for (c) after irradiation in the beam of the spectrophotometer with filter 2 . 


2000

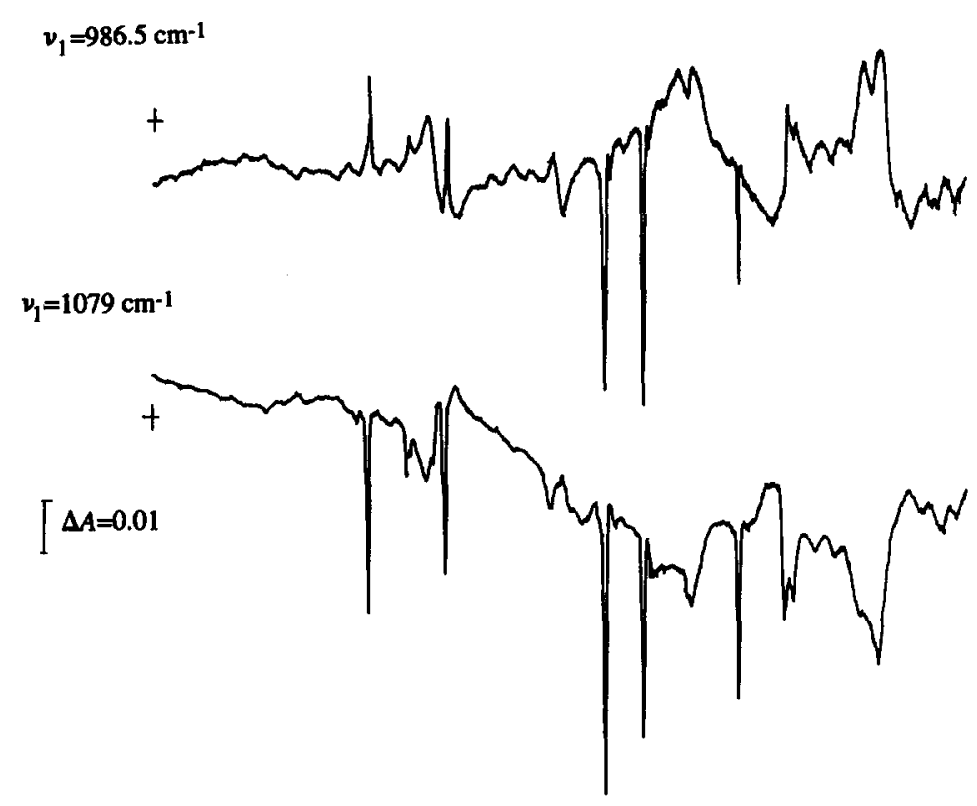

Fig. 5. Difference spectra after-before irradiation by $\mathrm{CO}_{2}$ laser lines at $\nu_{1}=986.5$ and $1079 \mathrm{~cm}^{-1}$. Same sample as for Fig. 3.

intensity changes in the $v_{\mathrm{s}} \mathrm{COC}$ region showed an intricate behaviour and did not allow accurate integrated intensity measurements, because the overlap of the $925 \mathrm{~cm}^{-1}$ feature (DME monomer) with the three lines at 923,920 and $917 \mathrm{~cm}^{-1}$ associated at different species as discussed below.

As illustrated, Fig. 5, the reverse photochemical effect was obtained using the R22 line $\left(1079.8 \mathrm{~cm}^{-1}\right)$. The $\mathrm{HI} / \mathrm{DME} / \mathrm{N}_{2} 1 / 1 / 500$ sample was firstly irradiated with the R38 line then irradiated with the R22 line. The fraction of aggregates which grew with the first irradiation disappeared with the second irradiation, the observed conversion indicating that the absorption coefficients for irradiated modes were of the same order of magnitude, under the experimental conditions used. Careful analysis of the two difference spectra given in Fig. 5 allowed the identification of complexed DME bands assignable to $\mathrm{Ag}_{1}$ from their behaviour upon IR irradiation. Thus four modes were seen to be sensitive to complexation and belong to the $\mathrm{Ag}_{1}$ aggregate: $1456.9 \mathrm{~cm}^{-1}\left(\mathrm{CH}_{3}\right.$ bending), $1165 \mathrm{~cm}^{-1}$ ( $v_{\text {as }} \mathrm{COC}+\mathrm{CH}_{3}$ rocking), $1092.5 \mathrm{~cm}^{-1}\left(v_{\mathrm{as}} \mathrm{COC}\right)$ and $917.2 \mathrm{~cm}^{-1}\left(v_{\mathrm{s}}\right.$ $\mathrm{COC})$; they are weakly red shifted with respect to that of the monomer DME. New bands belonging to the transformation product of $\mathrm{Ag}_{1}$ appeared at 1167.1, 1095.9 and $922.8 \mathrm{~cm}^{-1}$. As previously mentioned the only relatively well resolved band at $917 \mathrm{~cm}^{-1}$ cannot unfortunately allow accurate measurements of the disappearance of $\mathrm{Ag}_{1}$ because it is closed to that characterizing the $\mathrm{U}$ form of the one-to-one complex DME-HI.

Photolytic process. The most interesting observation resulting from the experiments is that a weak fraction of both cations disappears upon irradiation without appearance of significant new product bands. They reappear upon temperature increase below the annealing limit or under selective irradiation. This phenomenon is similar to that observed for one-to-one complexes involving $\mathrm{HI}$ and various bases, although the considered complexes of higher stoichiometries arise from strong hydrogen bond interaction. Hydrogen breaking converts the aggregates $\mathrm{Ag}_{1}, \mathrm{Ag}_{2}, \mathrm{Ag}_{3}$ in non-hydrogenbonded forms $U_{1}^{\prime}, U_{2}^{\prime}, U_{3}^{\prime}$ with nearby metastable minima. Species $U^{\prime}$ are only spectroscopically identified by some of the weak shifted DME vibrational modes at 1167.1, 
1095.9 and $922.8 \mathrm{~cm}^{-1}$, the $\mathrm{HI}$ mode being located very close to the monomeric line. After deposition in the dark at $20 \mathrm{~K}$ the two forms $\mathrm{Ag}$ and $\mathrm{U}^{\prime}$ coexist. Temperature increase upon $27 \mathrm{~K}$ or irradiation at low temperature lead to other different steady states, the rigidity of the host lattice and the low thermal bath energy preventing the return to the previous equilibrium. Thus, the intriguing spectroscopic and dynamical information obtained after irradiation with filter 4 depends on the previous distribution of $\mathrm{Ag}$ and $\mathrm{U}^{\prime}$ forms.

The $\mathrm{Ag} \rightarrow \mathrm{U}^{\prime}$ conversion, under our experimental conditions, is observed principally with irradiations in the $2500-1500 \mathrm{~cm}^{-1}$ region implying efficient excitation of $\delta \mathrm{CH}_{3}$ modes of the complexed base submolecule in the complex. However excitation with the $\mathrm{CO}_{2}$ laser line at $1079 \mathrm{~cm}^{-1}$ which is resonant with the $v_{\mathrm{s}}$ mode of the $\mathrm{Ag}_{2}$ complex lead also to the disappearance of $\mathrm{Ag}_{2}$ and $\mathrm{Ag}_{1}$ suggesting an $\mathrm{Ag}_{1} \rightarrow \mathrm{Ag}_{2}$ exchange process by a tunnelling mechansim which requires more study. The barrier height to induce the conformational change $\mathrm{Ag} \rightarrow \mathrm{U}^{\prime}$ in the aggregates seems lower than that observed for the photodissociation of the one-to-one complex. The possibility of a DME bond rotation not an HI rotation cannot be ruled out.

The $\mathrm{U}^{\prime} \rightarrow \mathrm{Ag}$ back conversion is observed upon temperature increase above $27 \mathrm{~K}$ and also by irradiation below $1200 \mathrm{~cm}^{-1}$ at low temperature proving an efficient vibrational excitation of the $v_{\text {as }} \mathrm{COC}$ and $\nu_{\mathrm{s}} \mathrm{COC}$ modes of the $\mathrm{U}^{\prime}$ species. The energy gained by the $\mathrm{U}^{\prime}$ species is probably greater than the $\mathrm{U} \rightarrow \mathrm{Ag}$ barrier; such an efficiency was also observed in the $\mathrm{U}$ pair conversion to the hydrogen-bonded one-to-one $\mathrm{CH}_{3} \mathrm{OH}: \mathrm{HI}$ complex [13] upon excitation of the $\mathrm{CO}$ stretching mode of $\mathrm{U}$. Monochromatic irradiation at $986 \mathrm{~cm}^{-1}$ in the broad band associated with $\mathrm{Ag}_{2}$ also induces $\mathrm{U} \rightarrow \mathrm{C}$ photoconversion. This surprising result is probably due to the existence of a combination mode involving a low torsional $\mathrm{CH}_{3}$ mode of $\mathrm{U}^{\prime}$ and which falls in coincidence with the $v_{\mathrm{s}}$ band assigned to $\mathrm{Ag}_{2}$.

Absorption coefficients of the modes implied in the $\mathrm{Ag} \rightarrow \mathrm{U}^{\prime}$ and $\mathrm{U}^{\prime} \rightarrow \mathrm{Ag}$ conversion appear of the same order of magnitude and global irradiation which contains all wavelengths is nearly without effect on the steady state obtained after deposition in the dark or after warming at $27 \mathrm{~K}$.

The observed photoconversion is complex and depends upon intramolecular and intermolecular energy migration from the DME modes to the reaction coordinate. More frequency selective measurements should be necessary for complete understanding of it.

The proton transfer between $\mathrm{Ag}_{1}$ and $\mathrm{Ag}_{2}$ was not accurately observed although the results obtained after irradiation with filter 1 seemed to indicate that excitation in $\mathrm{CH}_{3}$ stretching modes of DME could induce the proton delocalization.

The recent purchase of a tunable laser could allow us to resolve the unanswered questions about this system or other similar systems such as HI-acetone or HI-ethylene oxide for which formation of similar aggregates can be now better understood in the light of the present work.

Acknowledgement-One of us (A.S.) thanks Professor Knozinger for the cordial welcome to his laboratory in Siegen.

\section{REFERENCES}

[1] P. Schuster, in Intermolecular Interactions: from Diatomics to Biopolymer (Edited by B. Pullman), Chap. 4, p.425. Wiley, New York (1980).

[2] L. Schriver, A. Schriver and J. P. Perchard, J. Am. Chem. Soc. 105, 3843 (1983).

[3] C. Jouvet, C. Lardeux-Dedonder, M. Richard-Viard, D. Solgadi and A. Tramer, J. Phys. Chem. 94,5041 (1990).

[4] C. Crepin and A. Tramer, Chem. Phys. 156, 281 (1991).

[5] A. J. Barnes, L. Schriver, A. Schriver and J. P. Perchard, J. Molec. Struct. 240, 239 (1990).

[6] L. Schriver, A. Schriver and J. P. Perchard, J. Molec. Struct. 222, 141 (1990).

[7] R. E. Miller, J. Phys. Chem. 90, 3301 (1986). 
[8] H. Graener, T. Q. Ye and A. Laubereau, J. Chem. Phys. 91,1043 (1989).

[9] A. Loutellier, L. Schriver, A. Burneau and J. P. Perchard, J. Molec. Struct. 82, 165 (1982).

[10] Y. Hannachi, B. Silvi and J. P. Perchard, Chem. Phys. 154, 23 (1991).

[11] L. Schriver-Mazzuoli, J. Chem. Soc. Faraday Trans. 285,607 (1989).

[12] P. Bernadet, L. Schriver-Mazzuoli, A. Schriver and J. P. Perchard, J. Phys. Chem. 92, 7024 (1988).

[13] N. Bakkas, A. Loutellier, S. Racine and J. P. Perchard, Chem. Phys. 166, 167 (1992). 